\title{
AVALIAÇÃO DA SUSCETIBILIDADE NATURAL À INUNDAÇÃO NOS BAIRROS CAROLINA E SALGADO FILHO, SANTA MARIA/RS
}

\author{
Franciele da Silva $^{(a)}$, Daniel Junges Menezes ${ }^{(b)}$ \\ (a) Aluna do Programa de Pós-Graduação em Geografia da Universidade Federal de Santa Maria (UFSM), e-mail: \\ francieli17@gmail.com \\ (b) Aluno do Programa de Pós-Graduação em Geografia da Universidade Federal de Santa Maria (UFSM), e-mail: \\ danieljunges@hotmail.com
}

\section{Eixo: GEOGRAFIA FÍSICA E DESASTRES NATURAIS}

\begin{abstract}
Resumo
O objetivo deste estudo é avaliar a suscetibilidade natural à inundação nos bairros Carolina e Salgado Filho, localizados no município de Santa Maria/RS. A metodologia utilizada para contemplar o objetivo proposto utiliza a suscetibilidade como um dos parâmetros a serem considerados na identificação das áreas de risco. Com base nos resultados obtidos pode-se concluir que uma grande parcela, mais de 50\%, da área total dos dois bairros estão situadas sob áreas suscetíveis à inundação, áreas essas caracterizadas por declividades inferiores a $2 \%$ e/ou com a presença de depósitos fluviais. Este tipo de levantamento vem a atender a demanda de informações da área estudada, servindo como subsídio para realizar uma análise posterior, em escala detalhada, dos fatores que influenciam no zoneamento de áreas de risco.
\end{abstract}

Palavras chave: Segregação Especial; Suscetibilidade Natural, Inundação, Santa Maria/RS.

\section{Introdução}

O processo que vem ocorrendo ao longo dos anos e que está ocasionando intensas alterações espaciais e, sobretudo alterando a vida da população é a urbanização. Esse processo compreende dois aspectos fundamentais: o aumento da população das cidades e do número destas (médias e pequenas); e outro relacionado ao modo de vida e de trabalho, característicos da sociedade industrial.

Como consequência do processo de urbanização tem-se a supervalorização do espaço urbano, o que aumenta a segregação espacial e dificulta o acesso à moradia, fazendo com que a população de baixa renda busque alternativas de sobrevivência e venham a ocupar terrenos de alta suscetibilidade natural, os quais estão constantemente sujeitos às variáveis ambientais, acarretando em situações de risco para a população.

A suscetibilidade natural pode ser entendida como possibilidade de ocorrência de um evento e configurase em suscetibilidade a risco quando se tem em vista uma área ocupada e um evento adverso. Portanto, anteriores aos estudos de risco aparecem às avaliações de suscetibilidade natural, fruto das condicionantes ambientais, visando, muitas vezes, antever cenários que possam vir a configurar-se em áreas de risco. 


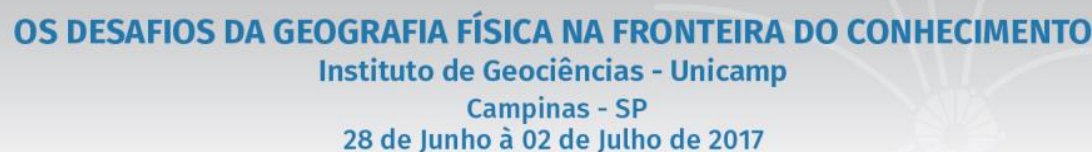

Estes estudos consideram os variados elementos que compõem a dinâmica natural da área a ser estudada, e a partir destas análises podem-se estimar quais os eventos e desastres naturais podem ocorrer em determinada área.

Segundo Lima (2010) a terminologia suscetibilidade é entendida como um ou mais atributos físicos que uma determinada área possui e que a torna potencialmente sujeita à ocorrência de desastres relacionados à dinâmica hídrica.

Todavia, neste trabalho, acrescentou-se a ação humana como um dos agentes intensificadores da suscetibilidade, pois, ao impermeabilizar o solo, por exemplo, o homem pode contribuir significativamente para uma alteração da dinâmica hídrica natural. É importante salientar que a terminologia suscetibilidade expressa apenas uma condição potencial, não uma certeza de que ocorrerá um desastre em nosso tempo histórico.

Embora a suscetibilidade natural se manifeste indistintamente nos diferentes sistemas ambientais, suas manifestações tornam-se mais evidentes nas áreas urbanizadas. Isso decorre principalmente da inexistência de espaços que sirvam para amenizar os efeitos das inundações, o elevado adensamento demográfico e principalmente a ocupação irregular dos espaços dotados de maior suscetibilidade natural, expondo os morados a uma série de riscos ambientais.

Neste trabalho, considerou-se o termo enchente como a elevação do nível regular de um corpo hídrico, devido às precipitações intensas e/ou prolongadas, sem extravasar os limites da calha da drenagem. Caso o aporte de precipitação seja suficiente para que a lâmina d'água da enchente ultrapasse as margens do arroio, atingindo terras normalmente secas, então se têm uma inundação. Essa definição é semelhante à utilizada pela Política Nacional de Defesa Civil (SNDC, 2007).

Na cidade de Santa Maria, a exemplo de outras cidades brasileiras, a má distribuição de renda, e por consequência a concentração fundiária urbana, levou a um processo de segregação sócio-espacial que originou vários loteamentos estabelecidos em áreas impróprias, muitas destas áreas inseridas dentro da Bacia Hidrográfica do Arroio Cadena.

O Arroio Cadena é um dos principais cursos d'água do município de Santa Maria/RS, o qual drena a maior parte da área urbanizada, onde praticamente todo o seu curso principal é ocupado por moradias. A ocupação urbana ultrapassa a planície de inundação do arroio, suas margens encontram-se bastante fragilizadas, sem a presença de vegetação ciliar, com traços fortes de erosão nas margens e alto grau de assoreamento do canal, agravados pela grande quantidade de resíduos depositados ao longo do arroio.

Tendo em vista o cenário apresentado, foram selecionados dois bairros que se localizam as margens do Arroio Cadena como objetos de estudo: o bairro Salgado Filho e o Bairro Carolina, como podem ser observados na figura 1.

DOI - 10.20396/sbgfa.v1i2017.2336 - ISBN 978-85-85369-16-3 


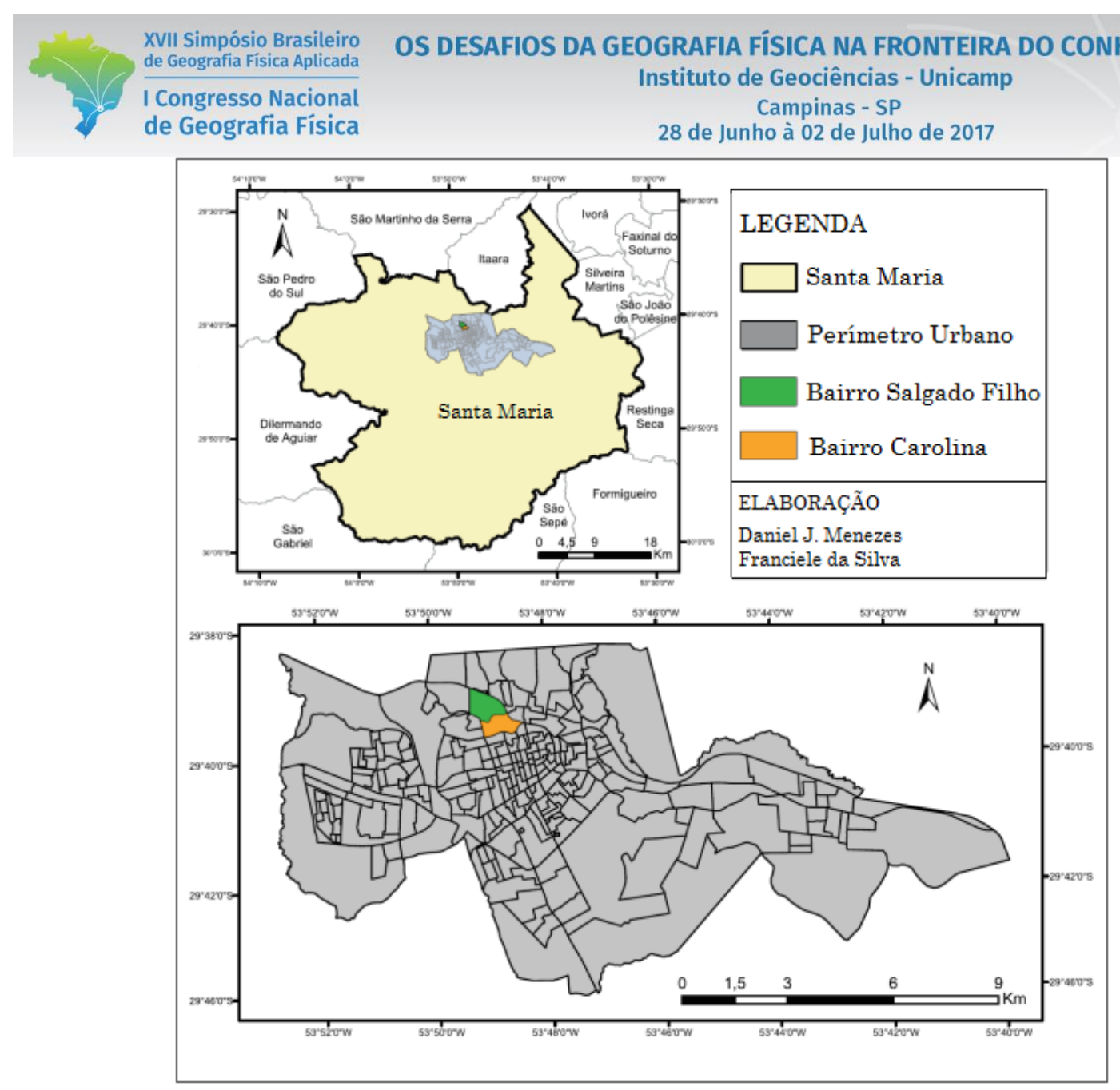

Figura 1 - Mapa de localização da área de estudo, Bairro Salgado Filho e Carolina, Santa Maria/RS.

Deste modo, o trabalho tem por objetivo identificar as áreas suscetíveis a processos de inundação nos bairros Carolina e Salgado Filho, ambos localizados as margens do Arroio Cadena, partindo do pressuposto que esta análise torna-se essencial para qualquer atividade de planejamento urbano que realmente tenha por finalidade uma democratização dos "espaços" da cidade e que procure melhorar a qualidade de vida dos que nela habitam.

Para uma análise sistêmica e que considere a dinâmica do ambiente na qual os dois bairros estão inseridos os mapeamentos foram elaborados considerando a área da sub-bacia a qual os dois bairros estão inseridos. Contemplando assim, todos os processos que podem estar incidindo direta ou indiretamente no local de análise e futuro planejamento.

\section{Metodologia}

Para a avaliação da suscetibilidade foram consideradas a rede de drenagem, o substrato geológico e a declividade da área. São consideradas suscetíveis as áreas que: 
- Tenham declividade inferior a 2\% e se localizem nas margens dos cursos d'água, que por serem áreas muito planas são suscetíveis a processos de inundações/alagamentos; Essas áreas são identificadas através do mapa de declividade do local;

- Apresentam declividades superiores a $15 \%$, onde os processos erosivos da vertente são mais acentuados, com necessidade de corte para a ocupação, sendo, portanto sujeitas a processos de movimento de massa. Essas áreas são identificadas através do mapa de declividade;

- Depósitos fluviais juntos as drenagens, determinados como geotecnicamente instáveis por Maciel Filho (1990); Tenham como substrato depósitos coluvionares, depósitos de tálus e sedimentos inconsolidados das várzeas junto às drenagens. Essas áreas são identificadas com base no mapa geotécnico da área de estudo;

Além da observância das seguintes condições:

- Áreas com proximidade inferior a 30 metros dos cursos fluviais, que por serem próximas ao leito são suscetíveis aos processos de inundação e solapamento das margens. A Lei Federal 6.766/79 estabelece as áreas junto aos canais como sendo non aedificandi e também conforme o Código Florestal Brasileiro, a ocupação dessas áreas é vetada. Essas áreas foram identificadas considerando a rede de drenagem;

- Áreas onde foram evidenciados processos de dinâmica superficial intensificado pelas atividades antrópicas. Essas áreas foram identificadas em campo, coletadas as coordenadas geográficas de cada local, e marcados os locais no mapa de suscetibilidade natural.

Combinando os mapas de Declividade, Áreas de Preservação Permanente (APP) e Geotécnico do local, acrescentando as coordenadas geográficas dos locais evidenciados pelos processos de dinâmica superficial em estágio intensificado pelas atividades antrópicas, foi possível a elaboração do mapa de suscetibilidade natural. Associado a esses procedimentos técnicos foi elaborado um mapa de ocupação do solo dos dois bairros, visto que a ação humana atua como um dos agentes intensificadores da suscetibilidade, pois, ao impermeabilizar o solo, por exemplo, o homem pode contribuir significativamente para uma alteração da dinâmica hídrica natural.

O mapa de declividade foi baseado na divisão do terreno em três classes: áreas com declives inferiores a $2 \%$, as quais correspondem às áreas planas onde predominam processos de acumulação; $2 \%$ - 5\% de declividade, áreas de acumulação; 5\% - 15\% sendo que a partir desta predominam os processos erosivos, adaptadas do IPT (Instituto de Pesquisas Tecnológicas de São Paulo).

Para mapear as Áreas de Preservação Permanente de margens foi considerado o Código Florestal Federal (BRASIL, 2012), lei mais restritiva, o qual atribuiu uma área de 30 metros em cada lado do canal principal destinados a essas áreas de preservação, em rios com até 10 metros de largura, considerando o caso da 


\section{OS DESAFIOS DA GEOGRAFIA FÍSICA NA FRONTEIRA DO CONHECIMENTO \\ Instituto de Geociências - Unicamp \\ Campinas - SP \\ 28 de Junho à 02 de Julho de 2017}

área de estudo. Como no local estudado não se encontram áreas de nascentes e áreas com declividades superiores a $45^{\circ}$, o estudo das APPs foi destinado apenas para as áreas de margens.

O mapa geotécnico, utilizado para caracterizar a geologia do local, bem como utilizado posteriormente para a delimitação das áreas suscetíveis, foi elaborado com base no georeferenciamento da carta Geotécnica de Santa Maria, elaborada por Maciel Filho (1992). Ao sobrepor o mapa geotécnico com a área dos dois bairros permitiu-se identificar as formações geológicas presentes na área.

Para a confecção do mapa de uso do solo, fez-se primeiramente a aquisição de imagens do software Google Earth Pro. Após aquisição das referidas imagens, as quais somam nove ao todo, procedeu-se a confecção de um mosaico que ao ser concluído foi configurado em 1500 DPI (Divisão de Processamento de Imagens), obtendo-se assim uma melhor resolução de imagem.

Com o objetivo de identificar o grau de impermeabilização dos bairros Carolina e Salgado Filho, as classes de uso do solo foram determinadas a partir da interpretação visual do mosaico de imagens, atribuindo-se classes aos diferentes tipos de cobertura do solo, baseando-se em princípios como cor, textura, tamanho, forma e conhecimento prévio do local; representada no mapa através de polígonos. As classes de uso utilizadas para a área foram agrupadas da seguinte forma:

1 - Muito Alta densidade ocupacional: áreas com ruas e calçadas pavimentadas e ocupações verticalizadas, construídas muito próximas umas as outras, com poucas áreas livres.

2 - Alta densidade ocupacional: áreas com ruas e calçadas pavimentadas adjacentes ao centro da cidade, com edificações construídas moderadamente próximas umas das outras, o que confere a essas áreas algumas superfícies livres.

3 - Média densidade ocupacional: áreas com construções próximas, com ruas não pavimentadas e com superfícies livres.

4 - Baixa densidade ocupacional: áreas residências com edificações não muito próximas umas das outras, com superfícies livres (quintais das casas onde se percebe vegetação de pequeno porte ou gramínea), e ruas pavimentadas ou macadamizadas.

5 - Campo: a classe é representada por campos com vegetação de pequeno porte e gramíneas em áreas não urbanas, assim como áreas arborizadas ou também com vegetação de pequeno porte em meio urbano e margens de cursos de água.

6 - Floresta: classe caracterizada por vegetação de médio e grande porte densamente compostas.

A análise do grau de impermeabilização teve como base o Coeficiente de Escoamento Superficial Direto (c), estabelecido por Wilken (1978) para o Município de São Paulo, adaptado às classes de uso do solo estabelecidas no presente estudo. Assim quanto mais próximo de zero estiver os valores deste coeficiente, 


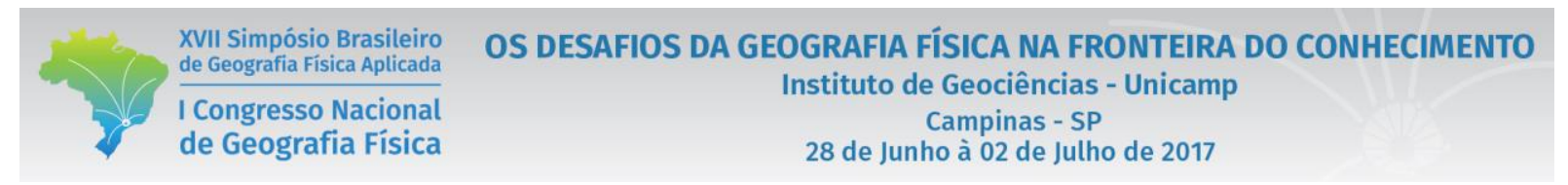

mais permeável encontra-se o solo de uma determinada área, levando-se em consideração o tipo de uso do mesmo.

O cruzamento das informações obtidas através do mapeamento dos dois bairros permitiu estabelecer um zoneamento da suscetibilidade natural em escala local, determinando três classes de suscetibilidade distintas. O mesmo cruzamento de informações dos mapas temáticos, somadas presença de imagem de satélite dos dois bairros permitiu confeccionar uma carta imagem da área de estudo, já objetivando, a partir da suscetibilidade estabelecida, constatar áreas de risco.

\section{Resultados e discussão}

Para que fosse possível analisar as condicionantes que tornam os dois bairros suscetíveis à inundação, foi necessário identificar e descrever as características físicas e peculiaridades presentes nos dois bairros.

No que tange a geologia, observa-se que grande parte do bairro Salgado Filho e quase que a totalidade do bairro Carolina, $\left(0,56 \mathrm{~km}^{2}\right.$ da totalidade de $1,08 \mathrm{~km}^{2}$ que compõem os dois bairros) está assentados sobre a presença de depósitos fluviais, os quais indicam que este afluente do Arroio Cadena já registrou volume e vazão suficiente para ocupar grande parte da área estudada, o que pode acarretar em processos de inundação. O fato dos depósitos fluviais serem considerados instáveis e muito suscetíveis a processos erosivos também caracterizam suscetibilidade natural a risco. Essas situações descritas podem ser observadas na figura 2.

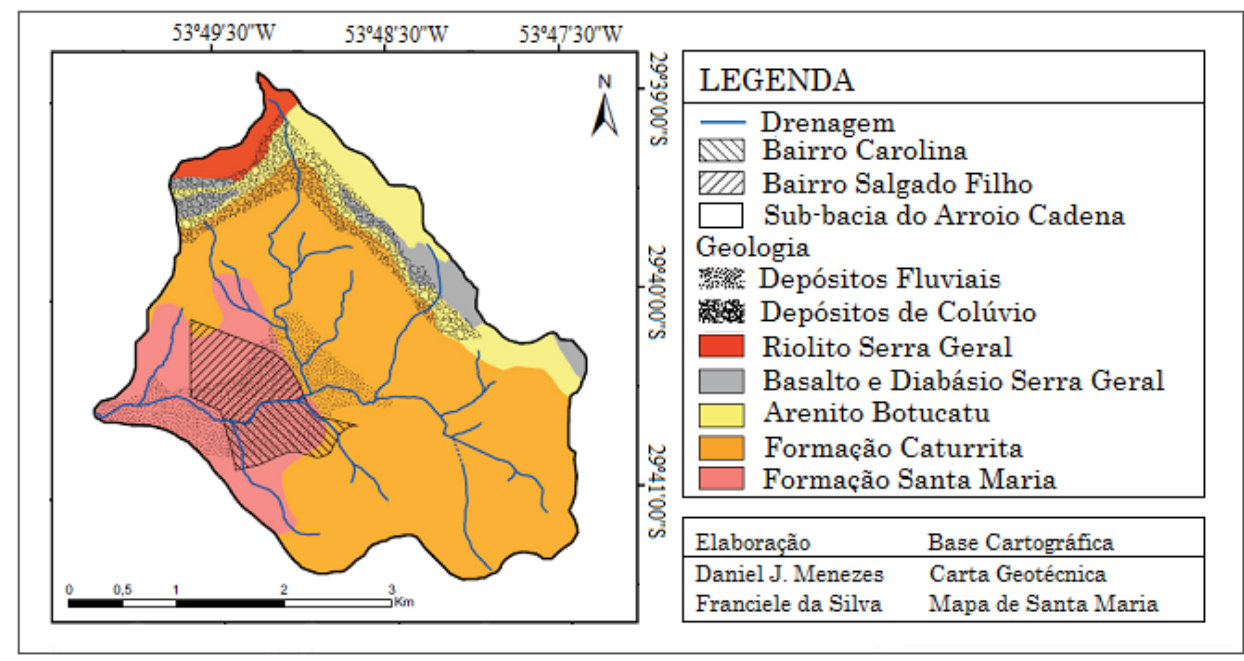

Figura 2 - Mapa geotécnico da sub-bacia hidrográfica que os bairros Carolina e Salgado Filho estão inseridos.

Através do mapa de declividade do local (figura 3) é possível observar que grande parte da área (0,43 $\mathrm{km}^{2}$ ) está predominantemente sobre áreas com declive inferior a $2 \%$, junto às margens do arroio, indicando a presença de uma grande área de suscetibilidade natural aos processos de origem hidrológica. 


\section{OS DESAFIOS DA GEOGRAFIA FÍSICA NA FRONTEIRA DO CONHECIMENTO \\ Instituto de Geociências - Unicamp \\ Campinas - SP \\ 28 de Junho à 02 de Julho de 2017}

A presença na parte norte do bairro Salgado Filho de áreas com declive superior a 15\%, onde os processos erosivos passam a ser mais intensos nas vertentes, pode indicar a suscetibilidade a movimentos de massa.

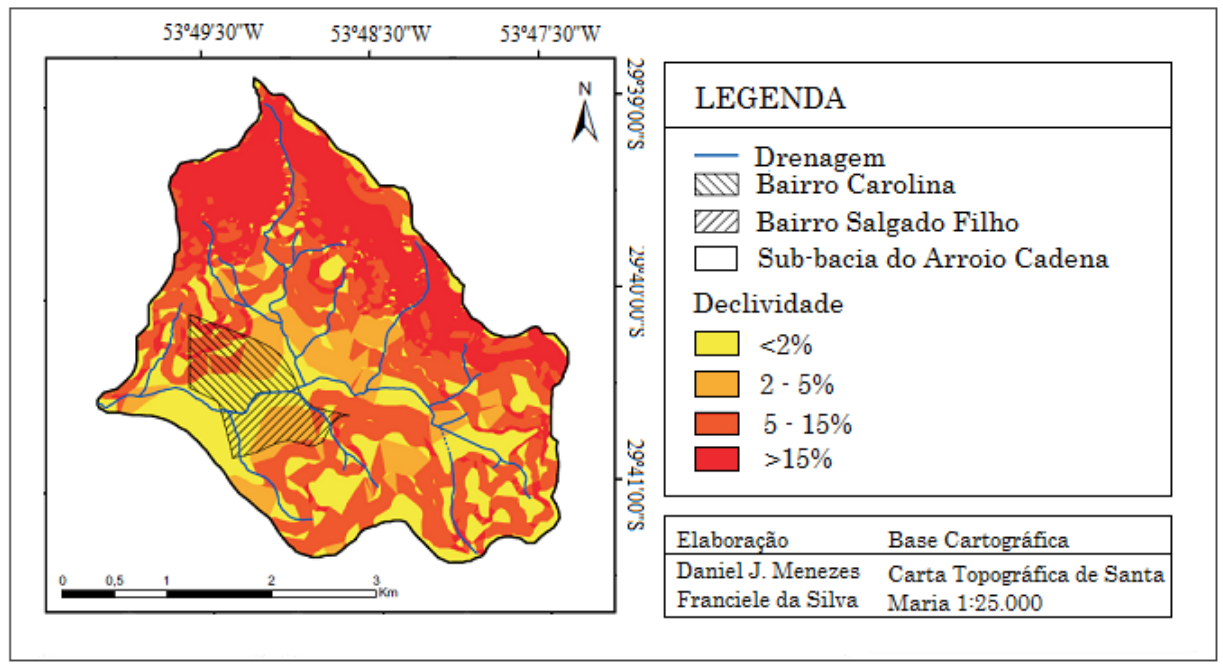

Figura 3 - Mapa de declividade da sub-bacia hidrográfica que os bairros Carolina e Salgado Filho estão inseridos.

A implantação das áreas urbanas acarreta em diversas consequências para o meio natural e a própria população, sendo que uma das mais diretas é a impermeabilização do solo, a qual provoca a diminuição da capacidade de infiltração da água e, logo, o aumento do escoamento superficial, fato que tem grande influência no incremento de inundações em meio urbano. Em períodos chuvosos, pelo bloqueio à infiltração, subutiliza-se a capacidade de infiltração em benefício do escoamento imediato, aumentando a carga sobre o sistema de escoamento pluvial e conduzindo ao transbordamento dos cursos d'água, alagamentos localizados, e aumento do poder erosivo. As áreas marginais sem vegetação, formadas por materiais inconsolidados, permeável e com lençol freático a pouca profundidade, que por ocasião das chuvas chegam facilmente à superfície ou para as áreas marginais (leito maior), propicia inundações e ação erosiva das margens ocupadas por habitações.

Portanto, para a área em análise, estabeleceram-se valores de coeficiente de escoamento superficial $(c)$ para cada classe homogênea, estando listados na tabela 1, juntamente com suas respectivas áreas totais e porcentagem a qual configuram o uso de solo nos bairros Carolina e Salgado Filho.

Tabela 1 - Classes de ocupação do solo e a respectiva determinação dos valores de escoamento superficial

\begin{tabular}{ccccc}
\hline & Classes de Ocupação do Solo & Área $\left(\mathbf{k m}^{\mathbf{2}}\right)$ & $\boldsymbol{\%}$ & $\mathbf{C}$ (coeficiente de escoamento superficial) \\
\hline $\mathbf{1}$ & Muito alta densidade ocupacional & 1,54 & 12,6 & 0,90 \\
$\mathbf{2}$ & Alta densidade ocupacional & 1,48 & 12,1 & 0,80 \\
$\mathbf{3}$ & Média densidade ocupacional & 3,29 & 26,8 & $0,50-0,80$
\end{tabular}


de Geografia Física Aplicada

I Congresso Nacional

de Geografia Física

4 Baixa densidade ocupacional
XVII Simpósio Brasileiro

OS DESAFIOS DA GEOGRAFIA FÍSICA NA FRONTEIRA DO CONHECIMENTO

Instituto de Geociências - Unicamp

Campinas - SP

28 de Junho à 02 de Julho de 2017

$$
6,4 \quad 0,20-0,50
$$

$2,82 \quad 23,1 \quad 0,10-0,30$

6

Floresta

2,28

18,6

0,05

Total

$12,20 \quad 99,6$

Organização: os autores.

Com base na tabela 1, podem-se destacar as classes que caracterizam ambientes naturais ou pelo menos sem urbanização, mas já com influencia antrópica. Uma destas classes configura-se em florestas, representando $2,28 \mathrm{~km}^{2}$ da área de estudo e com coeficiente de escoamento $(C)$ determinado, de 0,05 a 0,10, configurando-se em uma área de alta permeabilidade. Portanto, cabe salientar que, mesmo que estas áreas possuam cobertura vegetal de médio a grande porte, elas localizam-se nos locais mais declivosos da sub-bacia, com declividades acima de $15 \%$ como mostra o mapa de declividades (figura 3). Este fator é de fundamental importância, uma vez que em altas declividades a infiltração das águas pluviais é dificultada, principalmente quando ocorrem chuvas muito intensas, e assim o tempo de concentração é menor e o escoamento superficial se da mais rapidamente.

Com relação às áreas de campos, as quais representam $2,82 \mathrm{~km}^{2}$ da área de estudo, verificou-se a predominância de gramíneas, solo exposto, assim como campos de gado e pequenas lavouras. O coeficiente de escoamento determinado para estas áreas foi de 0,10 a 0,30 verificando-se grande variabilidade no que diz respeito à capacidade de infiltração das águas pluviais devido ao fato de não serem áreas homogêneas, com presença de solo exposto e pequenas áreas com vegetação arbórea de pequeno porte, além de campos em área urbana rodeados de construções.

Desta forma, a presença de remanescentes de vegetação preservados propicia a infiltração das águas excluindo aqui a tipologia do solo e suas características. Assim, ocorre um retardamento do inicio do processo de escoamento superficial, salvo em locais de solo exposto encontradas nesta área. Por estarem expostos à ação das águas, ocorre o selamento da camada superficial primeiramente através do impacto das gotas de chuva e também pela lixiviação, a qual carrega o material da superfície deixando a mesma sem os materiais que teriam o papel de reter a água tal qual nas áreas florestadas ou de gramíneas.

As demais classes determinadas verifica-se presença de edificações e arruamentos. Destas áreas a classe de ocupação do solo mais impermeabilizada ocupa uma área de $1,54 \mathrm{~km}^{2}$ (Muito alta densidade ocupacional) e tem um coeficiente de escoamento de 0,90 a 0,95 . Assim, pode-se verificar a pouca variabilidade no que diz respeito ao uso do solo e a infiltração das águas, configurando-se em uma área bastante homogênea com edificações próximas umas das outras e sem grandes áreas livres. Na análise do mapa de ocupação do solo (figura 4) verifica-se que nesta área grande parte do escoamento superficial é 
direcionada diretamente a sessão do canal do arroio Cadena, o qual faz divisa entre os bairros Salgado Filho e Carolina, enviando grande volume de água a esse local.

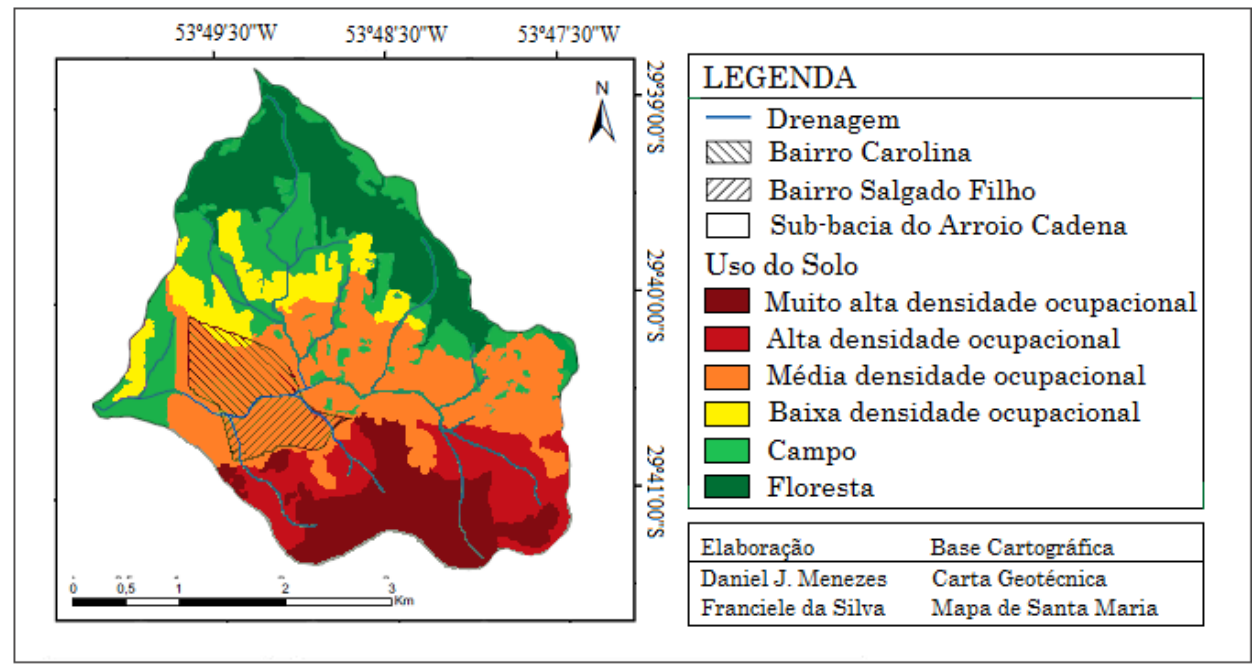

Figura 4 - Mapa de ocupação do solo da sub-bacia hidrográfica que os bairros Carolina e Salgado Filho estão inseridos.

Nas áreas de alta e media densidade ocupacional, as quais ocupam áreas de 1,48 e 3,29 km² respectivamente, ocorre à existência de áreas livres. Estas se configuram em ambientes que mesmo com intensa ação antrópica favorecem a infiltração das águas pluviais. Desta forma os coeficientes de escoamento determinados nestas áreas são de 0,80 a 0,90 e de 0,50 a 0,80 demonstrando grande variabilidade em função das áreas livres já mencionadas. Outro fator correspondente à variabilidade no coeficiente de escoamento destas áreas diz respeito aos arruamentos não pavimentados, os quais se constituem em locais de compactação do solo pelo intenso transito de automóveis e pessoas, não favorecendo a infiltração das águas e proporcionando o escoamento superficial mais rapidamente.

As áreas de baixa densidade ocupacional somam $0,79 \mathrm{~km}^{2}$, sendo a menor área de uso do solo determinada no presente trabalho. Assim as mesmas tendo um coeficiente de escoamento entre 0,20 a 0,50, configuram-se em áreas de grande variabilidade ocupacional com muitas áreas livres e arruamentos sem pavimentação.

As diferentes áreas de suscetibilidade natural foram estabelecidas após cruzamento dos mapas de declividade, geotécnico e ocupação do solo, os quais permitiram desenvolver uma visão integrada desses aspectos de extrema relevância para estabelecer as áreas que se ocupadas venham a desenvolver circunstancias de risco. $\mathrm{O}$ zoneamento das áreas suscetíveis à inundação foi dividido em 3 classes e pode ser observado na figura 5 :

- Suscetibilidade 1: As áreas planas do relevo representadas pelas planícies aluviais onde se encontram declividades inferiores a $2 \%$ são propícias, se ocupadas, a desenvolver processos de 
OS DESAFIOS DA GEOGRAFIA FÍSICA NA FRONTEIRA DO CONHECIMENTO

Instituto de Geociências - Unicamp

Campinas - SP

de Geografia Física

28 de Junho à 02 de Julho de 2017

inundações. Essas áreas são geotecnicamente impróprias, juntamente com os depósitos fluviais, por serem sedimentos quaternários inconsolidados, os quais possuem extrema fragilidade aos processos erosivos, desencadeado pela vazão das águas do canal. Além disso, são zonas saturadas, pois o lençol freático encontra-se próximo da superfície, facilmente acumulam água pluvial, mesmo em episódios de chuva de curta duração. A proximidade destas áreas em relação ao canal de drenagem também as torna suscetíveis aos processos de erosão de margem, sendo este fato somado a ocupação humana, indicando a possibilidade de áreas de risco. Estas áreas ocupam cerca 0,43 km² da totalidade de $1,08 \mathrm{~km}^{2}$ que compõem os dois bairros estudados.

- $\quad$ Suscetibilidade 2: Estas áreas embora não sejam delimitadas pela presença de declividades inferiores a 2\%, são áreas que estão assentados sobre a presença de depósitos fluviais, os quais indicam que este afluente do Arroio Cadena já registrou volume e vazão suficiente para ocupar grande parte da área estudada, o que pode acarretar em processos de inundação.

O fato de estes depósitos fluviais serem considerados instáveis e muitos suscetíveis a processos erosivos, conforme já citado, também caracterizam suscetibilidade natural a risco. Estas áreas ocupam cerca $0,12 \mathrm{~km}^{2}$ da totalidade de $1,08 \mathrm{~km}^{2}$ que compõem os dois bairros estudados.

- Suscetibilidade 3: Nos locais onde a energia do relevo é maior tem-se áreas que apresentam declividades superiores a 15\%, onde os processos erosivos da vertente são mais acentuados, sendo, portanto sujeitas a processos de movimento de massa. Esta condição aparece somente na parte norte do Bairro Salgado Filho e ocupam 0,01 km² da totalidade de $1,08 \mathrm{~km}^{2}$ que compõem os dois bairros estudados.

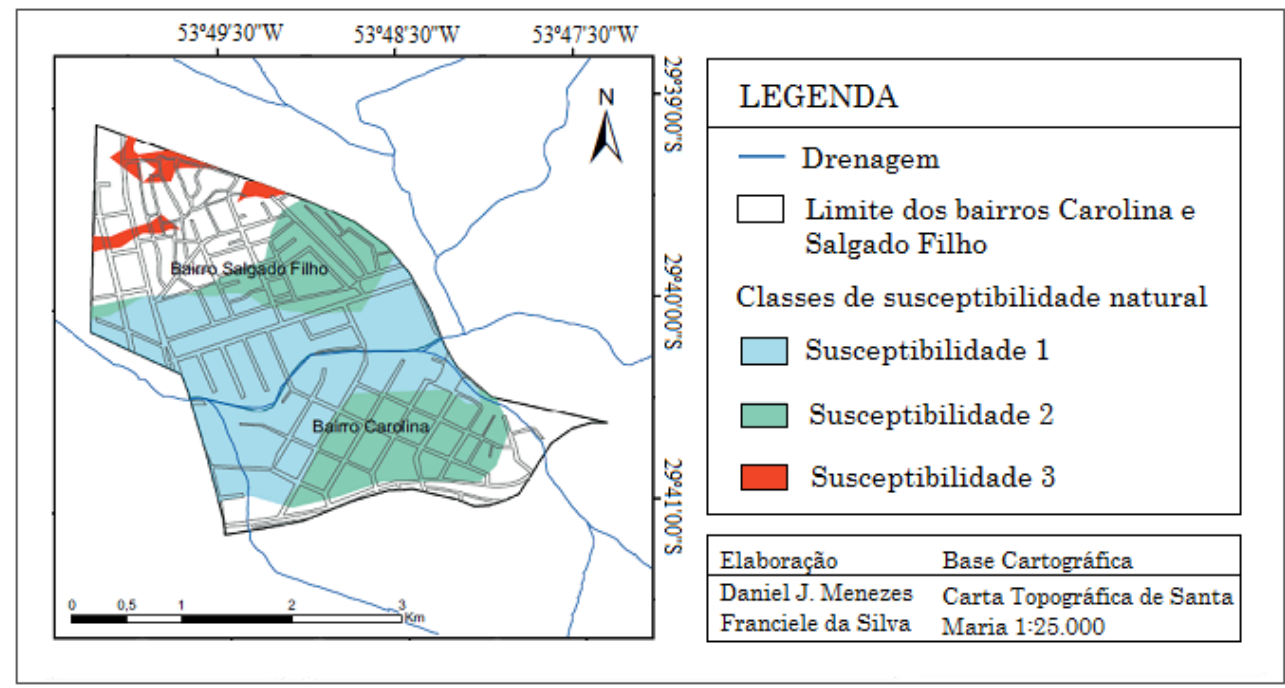

Figura 5 - Zoneamento da suscetibilidade natural à inundação nos bairros Carolina e Salgado Filho. 
O mesmo cruzamento de informações dos mapas temáticos, somadas a presença de imagem de satélite dos dois bairros permitiu confeccionar uma carta imagem da área de estudo (figura 6), já objetivando a partir da suscetibilidade natural estabelecida, constatar áreas de perigo e determinar o risco.

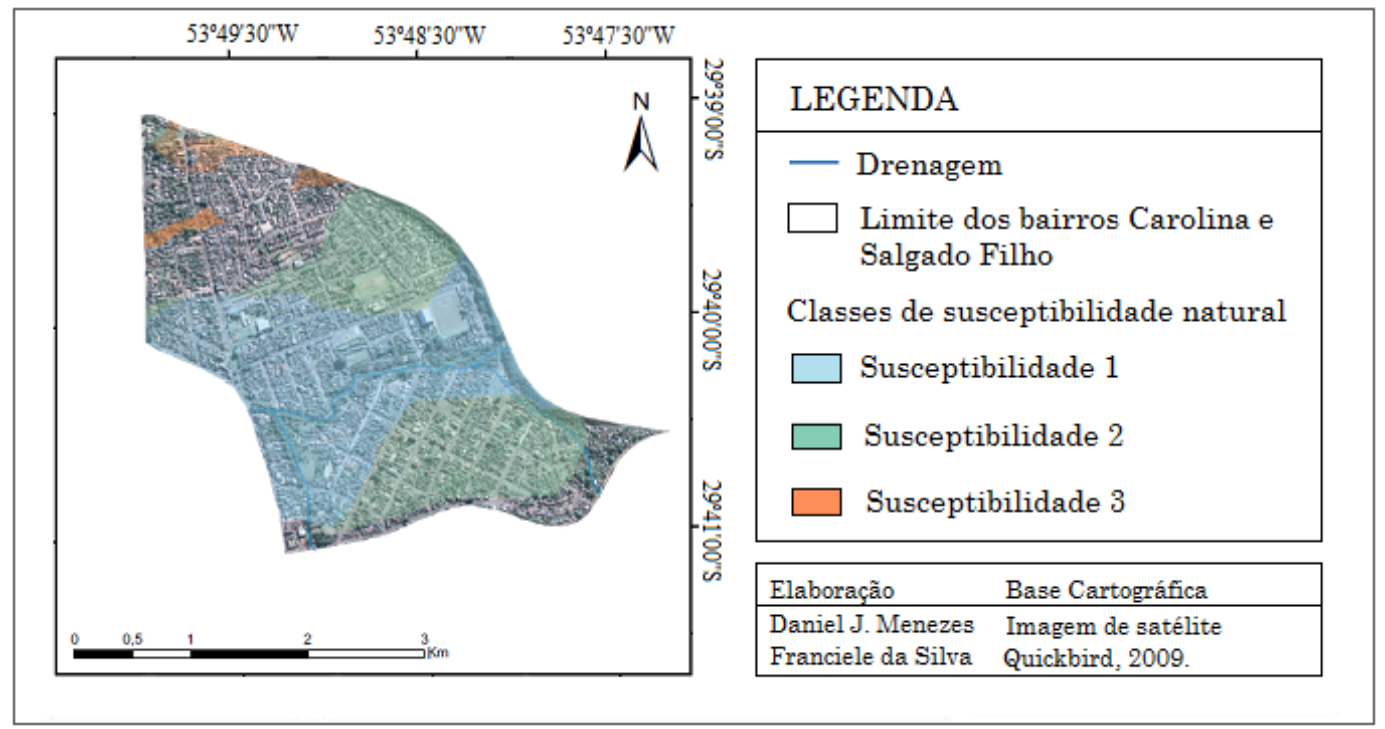

Figura 6 - Carta imagem do zoneamento da suscetibilidade natural à inundação nos bairros Carolina e Salgado Filho.

Através das imagens abaixo (figura 7) pode-se perceber a situação de suscetibilidade presente nos dois bairros, caracterizando um possível cenário de risco.

O que se pode concluir em relação à suscetibilidade analisada nos dois bairros é que as áreas com maior potencial englobam um conjunto de fatores, tais como baixas declividades, solos com reduzida capacidade de drenagem e formas de ocupação do local.

Através da análise foi possível abordar a problemática das inundações em áreas urbanas, o que acarreta severas consequências para as populações afetadas. Comumente, a gravidade dos danos (sejam pessoais ou somente materiais) tem uma relação direta com o grau de vulnerabilidade da população - e esta vulnerabilidade deriva de diversos fatores, principalmente das condições econômicas das populações expostas.

Embora não se esteja estudando a questão do risco, é importante acrescentar que cada porção das áreas suscetíveis pode responder de formas diferentes conforme a chuva precipitada (volume e distribuição temporal) e à distância em relação à drenagem.

\section{Conclusão}

O presente trabalho permitiu desenvolver um levantamento de informações pertinentes a suscetibilidade natural à inundação presente nos bairros Carolina e Salgado Filho, e caracterizar os processos atuantes 
neste meio. Este tipo de levantamento vem a atender a demanda de informações da área da sub-bacia servindo como subsídio para realizar uma análise posterior, em escala detalhada, dos fatores que influenciam para o zoneamento de risco.

Em uma perspectiva integradora que engloba natureza, humanidade e processos, este trabalho buscou compreender a dinâmica das inundações e mapear as áreas suscetíveis na sub-bacia que os bairros Carolina e Salgado Filho estão situados. Servindo, assim, como base para um planejamento futuro no que tange a identificação das áreas de risco do local.

\section{Agradecimentos}

Os autores agradecem a CAPES pelas bolsas de estudos concedidas, as quais auxiliam no desenvolvimento das pesquisas.

\section{Bibliografia}

BRASIL. Lei ${ }^{\circ}$ 6.766, de 19 de dezembro de 1979. Dispõe sobre o Parcelamento do Solo Urbano e dá outras Providências. Presidência da República, Casa Civil, Brasília, DF, 19 dez. 1979. Disponível em: <http://www.planalto.gov.br/ccivil/LEIS/L6766.htm> Acesso em: 15 jan. 2017.

. Lei n ${ }^{\circ}$ 12.727, de 25 de maio de 2012. Institui o Código Florestal. Presidência da República - Presidência da República, Casa Civil, Brasília, DF, 25 maio. 2012. Disponível em: < http://www.planalto.gov.br/ccivil_03/_ato2011-2014/2012/lei/112651.htm>. Acesso em 08 nov. 2016

MACIEL FILHO, C. L. Carta Geotécnica de Santa Maria. Santa Maria: Imprensa Universitária - UFSM, 1990.

IPT. Manual: Ocupações de Encostas. São Paulo: IPT - Instituto de Pesquisas Tecnológicas de São Paulo, 1991.

LIMA, L. M. M. De. Mapeamento da suscetibilidade à inundação na bacia hidrográfica do Arroio do Salso, Porto Alegre - RS. 2010. Dissertação (Mestrado em Geografia) - Universidade Federal do Rio Grande do Sul, Porto Alegre.

SNDC - Secretaria Nacional de Defesa Civil. Política Nacional de Defesa Civil. Brasília: 200787 p. Disponível em: 〈http//:www.defesacivil.gov.br/publicações/publicações/pndc.asp>. Acesso em: 14 de out de 2016.

WILKEN, P. S. Engenharia de Drenagem Superficial. Companhia de Tecnologia de Saneamento Ambiental (CETESB), São Paulo. 1978. 